DOI: 10.21625/resourceedings.v2i3.631

\title{
Sacred places: spaces for a dialogue among cultures
}

\author{
Olimpia Niglio $^{1}$, Luigi Guerriero² \\ ${ }^{1}$ Universidad de Ibagué, International School, Colombia,; AIRC International Research Center, Vienna, Austria \\ ${ }^{2}$ Università della Campania "Luigi Vanvitelli”, Italy \\ Email: olimpia.niglio@gmail.com
}

\begin{abstract}
Background. The construction of a sacred space identifies a place where men realize a direct relationship with their God, qualifying this space as the absolute center of the existence, regardless of its location and its definition.

In the sacred places, the geometric-dimensional relations, that define each space, are enriched with the temporal connotation, making more explicit the inseparable relationship between the architecture and the historical process (to stay erected in front of the history, following the more convincing anthropological meaning of the building action) with the material changes of the same architecture.
\end{abstract}

Results. Then, each sacred place is the center (from which an axis is inevitably outlined) of a spatial dimension that is emancipated from pure physical conditions and it forces to involve tools of unusual analysis that fit the specificity of the use (in other words, the symbolic character).

The sacred place assumes the role of an instrument of synthesis (of manifesto) that allows a vision of the world ables to build the dialogue among the cultures, overcoming the limits of the individual perspectives and fitting a community program based on the sharing of the Human Values.

Conclusion. Given these premises, the paper reconsiders some studies of the history of the architecture that has given specific attention to the issue of the sacred place that is also seen as material and intangible space, where men meet their God, their self and the community. The contribution also analyzes experiences of realization of sacred spaces, between the second half of the nineteenth century and the first half of the twentieth, examining religious architecture in different geographic areas and with multiple cultures. These sacred spaces have often allowed overcoming the fracture caused by colonial politics, favoring the regeneration of the meaning of the sacred places.

(c) 2019 The Authors. Published by IEREK press. This is an open access article under the CC BY license (https://creativecommons.org/licenses/by/4.0/).

Keywords

Sacred places, Intercultural dialogue, Human Values, Cultural syncretism

\section{Introduction}

The space (from Latin: spatium) represents an unlimited and indefinite place that assumes a physical connotation through material elements that describe and circumscribe it. This materiality represents the narrative nucleus that the community recognizes to the space lived by attributing it specific "personalities". A space steeped in material and intangible elements, natural and cultural references, defines the landscape of men.

The Explanatory Report to the European Landscape Convention (Florence, 2000), to article 38 defines that the "Landscape is defined as a zone or area as perceived by local people or visitors, whose visual features and character 
are the result of the action of natural and/or cultural (that is, human) factors. This definition reflects the idea that landscapes evolve through time, as a result of being acted upon by natural forces and human beings. It also underlines that a landscape forms a whole, whose natural and cultural components are taken together, not separately"

The landscape of men is, therefore, the result of the objectification of reality that has been built through long and complex processes of social and cultural sedimentation. It is a rich cultural heritage that has designed the territories, defining and delimiting the space through content sedimented in time.

The Italian writer Emilio Sereni affirms that "landscape is the world, its mystery, its secret" (Turri, 2003) and therefore constitutes a set of meanings and narratives that have materialized space in respect for human needs. In these narratives, we identify many paths and among them the issue of the sacred space. In the constant material demarcation of the space and the landscape of men, the meaning of the sacred assumes an important perceptive value. The sacred space becomes the place where the individual encounters what is other by itself. The rituals, the pilgrimages, the liturgies, the memories, the burials, are all ways to recognize the sacredness of a space (Bartolomei, 2017).

Certainly, the continual questioning of men in search of his own origins constitutes a fundamental basis for understanding the sacred value of a space. Such archetypes are born as the tree, the stone, the hypogean environments, which help men to materialize the sacred value of a place. These references are at the heart of anthropological literature and human geography, and scientific debates on the subject constitute an important basis for the development of this contribution.

\section{Sacred space}

The history of humanity has handed down to us many archetypes, important testimonies of the different communities. In the western territories are preserved mainly castles, fortified palaces, churches and monasteries, cities with walls, all examples that describe the materiality of specific cultural codes. Differently, in Oriental, African and IndioAmerican cultures these codes have produced different results and the sacred dimension of space has taken on fundamental value. While in the West this sacredness has materialized through the edification of recognizable elements to the community, differently in the Oriental cultures the relationship with the indefinite, and therefore with the unlimited space, assumes a connotation important in the definition of sacred space.

A recent research, entitled "Sacred Landscape: An Invaluable Resource between Knowledge and Sustainable Local Tourism Development" coordinated at University of Bologna (Dallari \& Niglio, 2018), has shown that the sacredness of space and the anthropized landscape depend exclusively from the cultural contexts of reference and that this sacredness has no connection with the materiality except with the perceptive ability of men to hear, to feel and to know what is not tangible.

The different cultural paradigms show wich "since immemorial times, many communities have learned how to respect the power of natural elements, also establishing sacred and spiritual relationships with nature and diversity which are conveyed through the landscape. Even today, in many countries and especially in the Far East, Oceania and Latin America, native communities regard nature as a spiritual experience permeated with feelings of reverence, peace, humility, gratitude, harmony, unity and, most of all, a sense of belonging and identity" (Niglio, 2018).

In an interesting report by Makoto Motonaka the researcher affirms that the sacred space is a mirror of the spiritual and ecological ethos of the communities and he introduces the concept of "Associative Cultural Landscapes" (Motonaka, 2001). These associative properties depend on the cultural paradigms of reference. On this topic in the last years, the International Union for Conservation of Nature (IUCN) has realized very important publications that have outlined definitions, approaches, and procedures for the valorization of the sacred values of the sites, respecting the different cultural codes of the territories (Wild \& McLeod, 2008).

However, the study of sacredness requires a holistic vision, available to undertake a path not strictly material and at the same time able to read multiculturality without conditionings. Sacred sites are outstanding assets of the whole of humanity and for this reason, it's very important this holistic approach that we help to understand the indefinite. 
In this non materiality, the sacred value of a place assumes a cultural and social dimension, where its measure is defined by the modalities that the community adopts in recognizing the sanctity. The sacred dimension of a place is interconnected to the social organization of space, to the symbols, to the different archetypes that history has handed down to us. Good reading semiotics is fundamental to interpret the different meanings, the signs, the traces that in the course of history the communities have sedimented in the different territories.

The research of the sacred dimension becomes a complex game of "different meanings" that induce us to continually interrogate ourselves on the symbolic value of this space, on its organization and on the effects of the sacred experience that everyone perceives in Respect of their own cultural codes (Marroni, 2001).

The indefinability of the sacred leads to reflect on the topological aspects of the place, on the symbolic role of human perception, on the significance of transcendence and immanence in different cultures. Thus, analyzing the sacred value of space implies a non-manualist, non-nozionistic, but deductive approach to a complex and ever-changing reality. On this subject, many civilizations have been confronted so much that the value of the sacred was one of the central themes of the social structuring of late antiquity populations of which today still retain important traces in the different cultural syncretisms.

\section{Multicultural experiences}

A sacred symbol very common to different cultural codes is certainly represented by the mountain: Olympus for the ancient Greeks, Mount Sinai for Jewish-Christian culture, the Machu Picchu Mountains in Peru for the Inca civilization, the Kilimanjaro in Tanzania, summit sacred and inviolable for the Wa Chagga tribe, Mount Fuji in Japan that together with Mount Tate and Mount Haku constitute the three sacred mountains for the Shintoists and still the great rocky monolith Ayers Rock in Australia, from 1987 World Heritage site.

Symbolic and sacred elements to which are flanked also anthropic references as the great Aztec treasures in Tenochtilan (Mexico City) with the famous temple Mayor reminiscent of the pyramids built by the Egyptians in the North African desert, the temples of Angkor Vat in Cambodia, the Borobudur on the island of Java, the Sacri Monti of Varallo in Italy.

All these examples have a common denominator: the experience by which men have tried to establish a dialogue with the supernatural, with his own God. In this relationship, the men have identified, delimited and built his own sacred space.

The ancient traditions have handed down a concept of sacredness connected to the natural environment. The encounter between men and divinity has always been mediated by natural elements: forests, caves, rivers, mountains that have become shrines of veneration. An example is the Mount Yasumandake on the island of Hirado in Japan, a sacred mountain for the Shintoists but also for the small Christian community, important also for the large rice plantations (Figure 1).

Also in the West, the naturalistic component played an important role, especially in the Greco-Roman culture. The ancient writers always connected the cult of the Gods to natural places. For example, Plinio (Naturalis Historia, II, 97, 207/208) tells the cult of the Goddess Mefite in Irpinia (Campania, Italy) in the valley of the River Ansanto where the Catholic sanctuary of Rocca San Felice is located: a sacred place where the pagan cult of the goddess Mefite venerated In a forest bathed by a river and volcanic territory (Figure 2). 


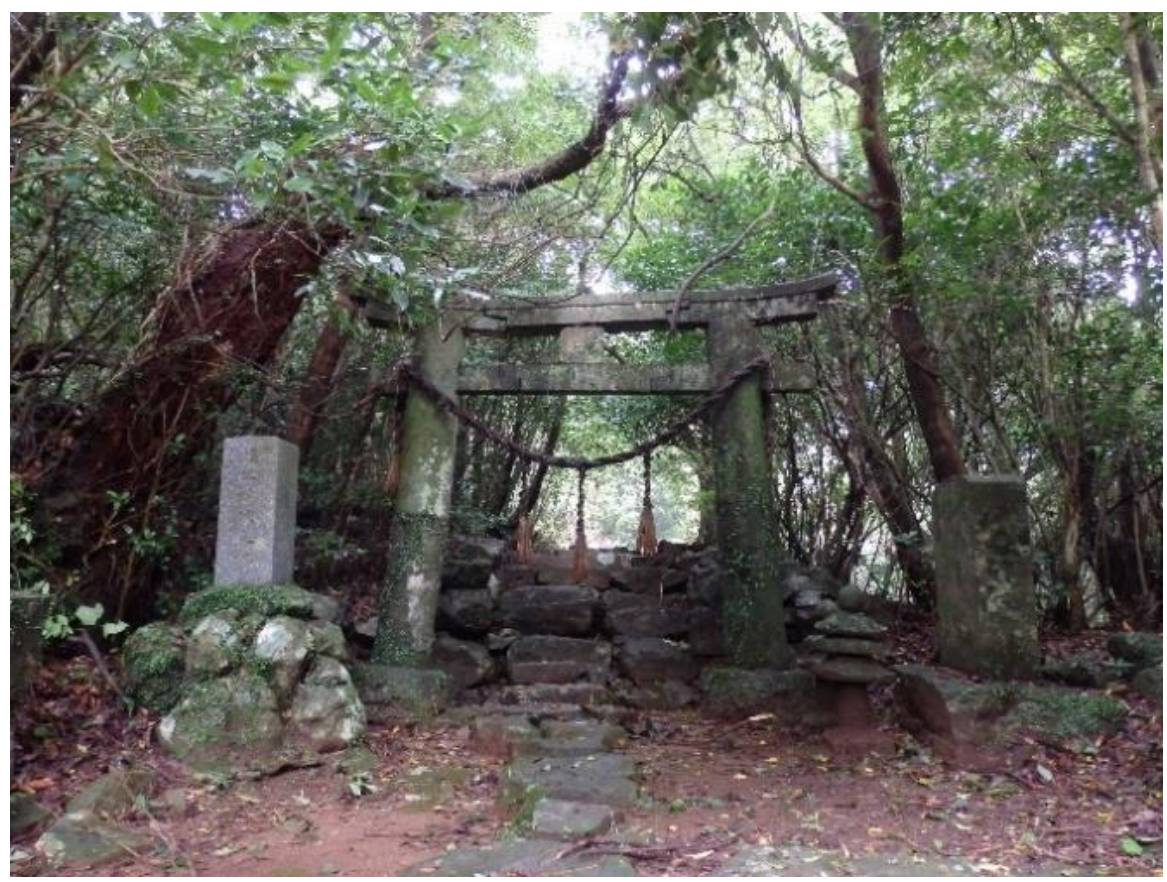

Figure 1. Yasumandake, sacrd montain (Hirado, Japan)

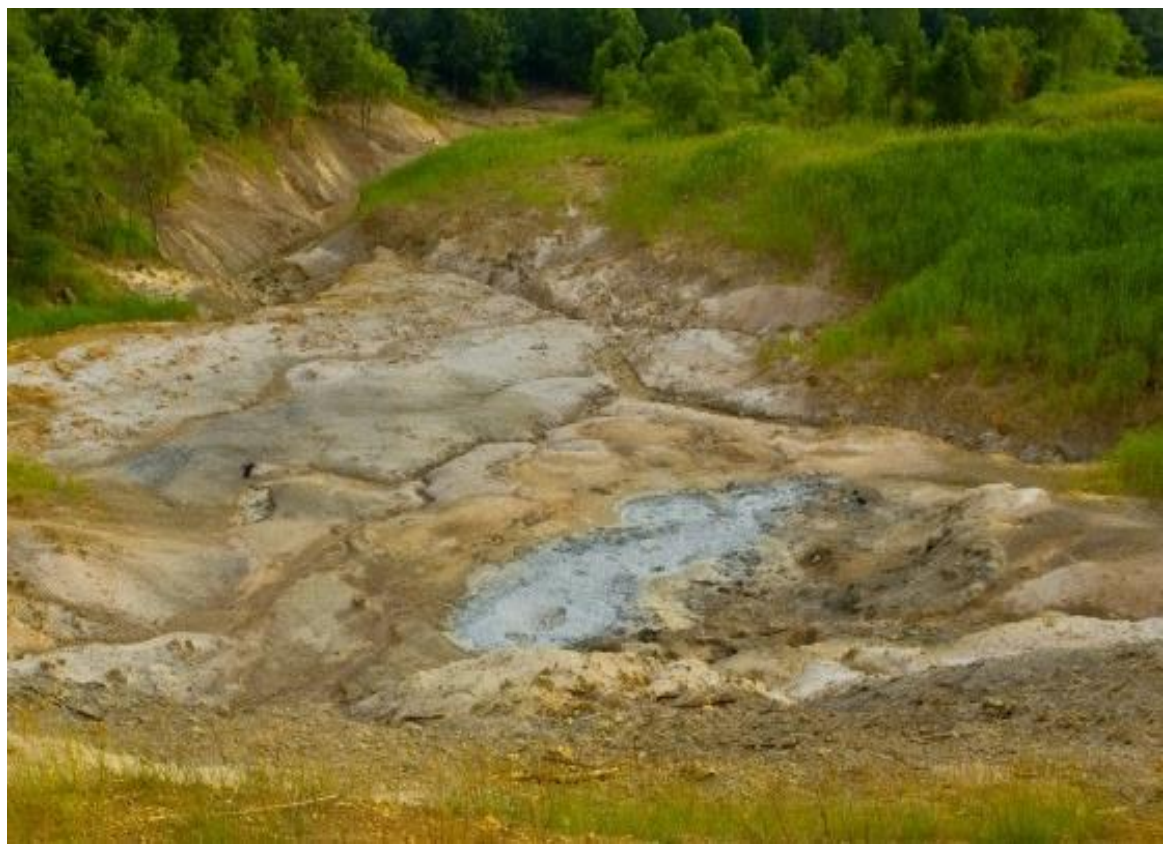

Figure 2. Ansanto river, Rocca San Felice (Campania, Italy)

The modern cultural anthropologic has studied numerous phenomena of overlapping pagan cults with Christian cults that retain many ancient rituals and devotions. This syncretic aspect is a common occurrence in many parts of the world. The cultural syncretism in fact intervened by modifying the characteristics of the rites and the sacred meaning of the places.

In the multicultural experiences analyzed in different parts of the world, it emerges that the theme of the sacred is of diversified shapes and dimensions whose measure is always represented by the cycle of life and by the dialogue with the indefinite. An exemplary case of the meeting of the West with the new continent. In Colombia on the Cordillera of the Eastern Andes, in the Department of Boyaca, in the seventeenth century, the Dominicans built the convent next to the sacred place of purification of the Muisca civilization. It's the Infiernito Solar observatory with large sacred stones, symbols of fertility, which perimeter areas of veneration and burial (Figure. 3). Sacred spaces transformed into material emblems that in the dialogue between cultures have given rise to built places. Thus develops the 
architecture of the sacred places. A very significant example is the Sincretic sacredness in the village El Rincón in Cuba where the Catholic temple of San Lazzaro was built in 1781. In the same place, there were already rituals of African tradition (Figure. 4). Sacred space that becomes architecture, then geometric space (Rausenberger, 2018).

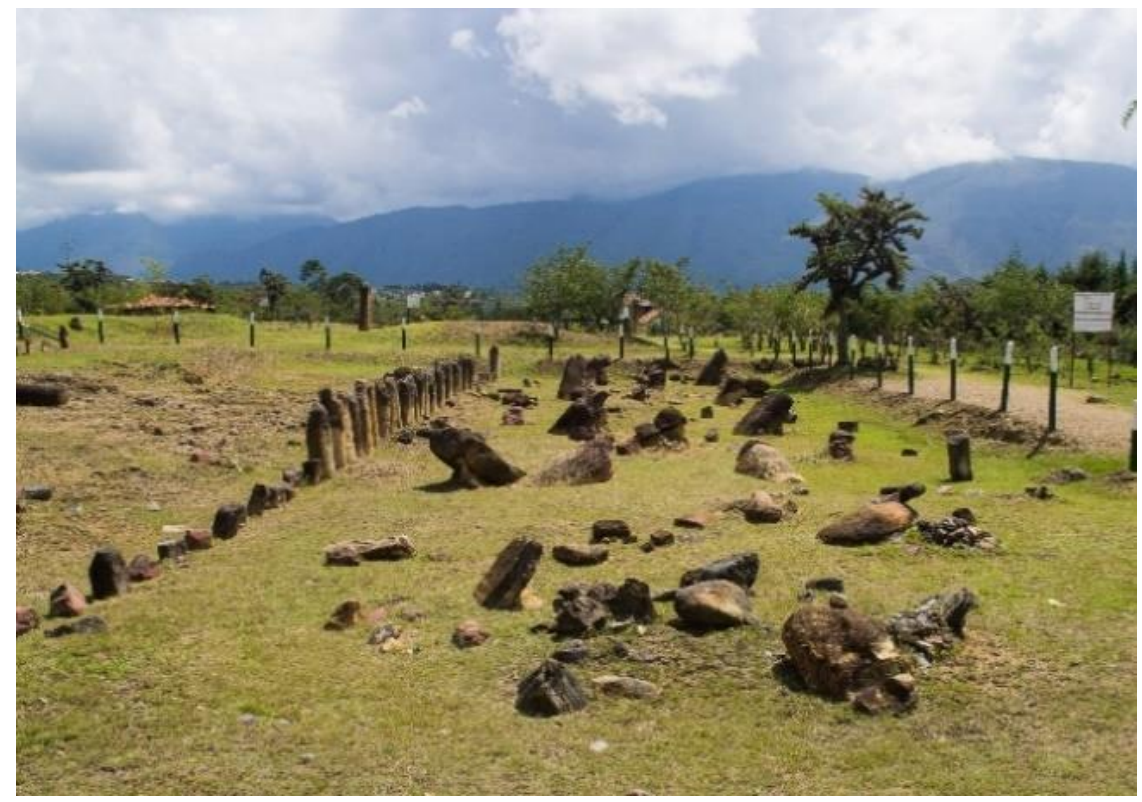

Figure 3. Colombia, Infiernito solar observatory Muisca

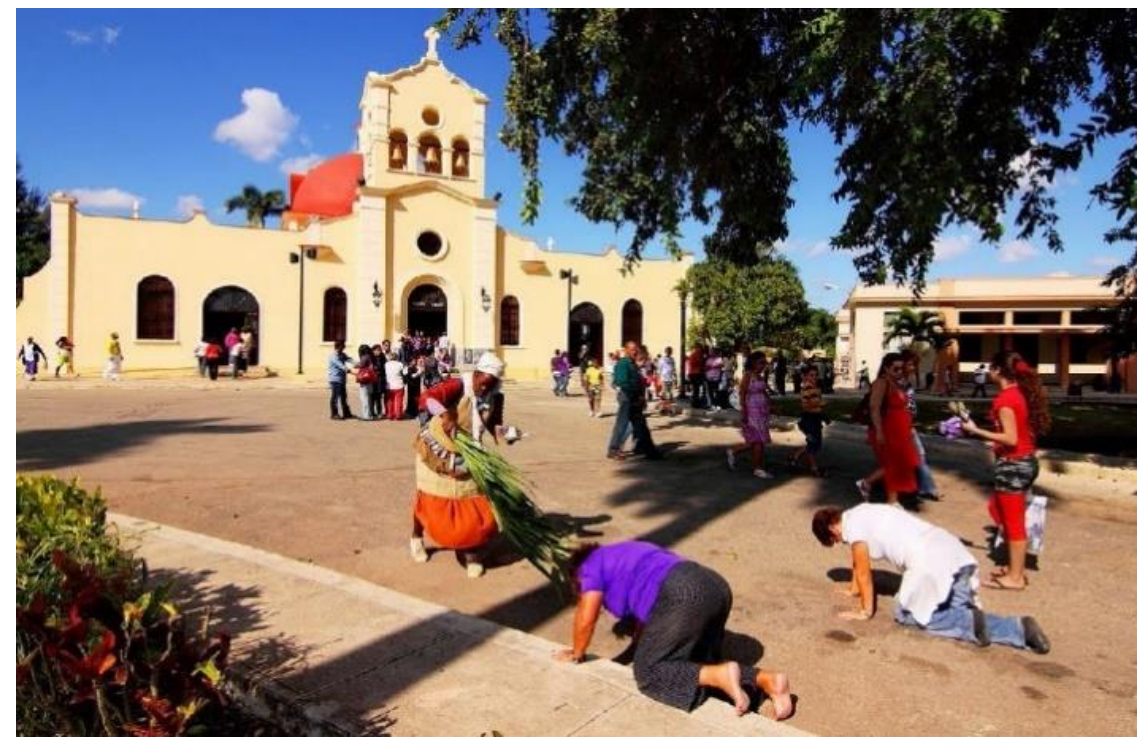

Figure 4. San Lazzaro, Cuba. Between Catholics and Santeria

This shows how the sacred dimension of a long finds ancient roots, from the earliest community settlements when man began to organize in society. However, in the evolutionary course of history, the concept of "holy place" has undergone considerable transformations, mainly connected with the different philosophical and religious systems that can be found in the different regions of the world (Gideon, 1984).

The history teaches us that sacred value is for men who in this value have sought the justification to his origin and to needs. The first important manifestation of the sacred is in the cosmic order, in the reading of space. This cosmic order materializes through signs, symbols, languages that have codified oral traditions but also architectural manifestations. In all these cultures the initiatic rites have identified sacred places for cults and human sacrifices. The sacred value of a place also exists without religion. The sacredness thus becomes the instrument by which the men take possession of the space, of the chaos, of the cosmos through an ontological process. When this process needed to attribute symbolic value to the configuration of the cosmic space, at this moment the architecture of the sacred space was born. 
However, the history of the architecture of sacred space, both in the West and in the East, coincides with the history of the liturgy and therefore the geometric form is a spatial symbol of the liturgy. This symbol has had important transformations in relation to the evolutions of the liturgical paradigms (Sicignano, 2012; Grisi, 2019). The sacred architecture, with its materiality, has intended to go beyond the cosmic and metaphoric vision of reality. These architectures have delimited spaces of a world that belongs to an indefinite cosmos but at the same time have built bridges to unite a man to his God. The architect, artist, and writer of these sacred spaces, thus becomes Pons Pontis or the costructures of bridges and dialogues between man and the superhuman (Tagliaferri, 2014).

Especially since the second half of the nineteenth century we have witnessed numerous reflections on the new project of the sacred space built. Numerous projects of "deconstruction" of sacred architectures, to "reconstruct" new liturgical spaces or even new secular functions, have often compromised archetypes and original cultural symbols. This issue now assumes an even more important role if analyzed in relation to the phenomena of globalization and multicultural dialogue which have contributed to the revision of formal paradigms and social conventions. A reflection that finds interesting feedback in numerous projects for the revision of the consolidated sacred Spaces and in the design of new forms of sacredness. However, this important dialogue between cultures requires a consolidated contribution among several disciplines: History of art, philosophy, ethnology, liturgy, theology, and architecture. Therefore the search for the meaning of today's sacred space cannot be separated from this interdisciplinary nature.

\section{Conclusion}

In 2009 Alksej Lidov, Russian bizantinistic historian, commented on "The positivist ideology of the nineteenth century, within which formed the majority of the current disciplines, did not see in the ephemeral sacred space a subject of investigation: The majority of the disciplines is related to concrete materials: paintings, architectures, rituals or written texts. The creation of sacred spaces has not even received a place in the current system of humanistic studies, whose structure has been determined by object-centric models, of the description of the universe. Therefore, logically, a field of study has not been formulated and therefore a discipline with an independent methodology and a conceptual language" (Lidov, 2009, pp.11-34.). Meanwhile, the sacred space, despite finding very ancient origins, has never taken on a disciplinary autonomy. The experiences, although only illustrative presented in this contribution, demonstrate the importance of the topic and the need for specific research insights. These insights will have to be realized in respect of different cultures. We hope that this contribution can stimulate future research and debates.

\section{References}

Bartolomei, L. (2017). "Signum consolationis". La costruzione dello spazio sacro e il paesaggio. In Boselli G, editor. Abitare, Celebrare, Trasformare (pp. 123-140). Magnano: Edizioni QIQAJON Comunità di Bose.

Dallari, F., Niglio, O. (2018). Editorial. Almatourism Special Issue, 8 : I-IV.

Gideon, S. (1984). Spazio, Tempo, Architettura. Milano: Hoepli.

Grisi T. (2019). Architettura liturgica. Un dizionario essenziale. Siracusa: LetteraVentidue Edizioni.

Lidov, A. (2009). Ierotopia. Creazione di spazi sacri come forma di creatività e oggetto di ricerca storica. In Lidov A. Ierotopia. Icone spaziali e immagini-paradigmi della cultura bizantina. Mosca: Ed. A.

Marrone, G. (2001). Corpi sociali. Processi comunicativi e semiotica del testo. Torino: Einaudi.

Motonaka, M. (2001). Report of the Thematic Expert Meeting on Asia-Pacific Sacred Mountains (Waka-yama, Japan, 5 to 10 September 2001). Helsinki.

Niglio, O. (2018). Sacred Landscape for a Global Approach. Almatourism Special Issue; 8 : 1-16.

Plinio (1984). Naturalis Historia (Storia Naturale), Antropologia e zoologia. Vol. II. Torino: Einaudi.

Rausenberger, J. (2018). Santurismo: The Commodification of Santería and the Touristic Value of Afro-Cuban Derived Religions in Cuba. Almatourism Special Issue, $8: 150-171$.

Sicignano, E. (2012). L'architettura dello spazio sacro. Soveria Mannelli: Rubbettino Editore.

Tagliaferri, R. (2014). Sacrosanctum. Le peripezie del sacro (Studi religiosi). Teologia 3 (39) : 475-476.

Turri, E. (2003). Il paesaggio degli uomini. La natura, la cultura, la storia. Bologna: Zanichelli.

Wild, R., McLeod, C. (2008). Sacred Natural Sites: Guidelines for Protected Area Managers. Gland, Switzerland: IUCN. 